\title{
DETERMINING CHARACTERISTICS OF TEACHERS, STUDENTS AND EDUCATIONAL MANAGERS IN THE 4.0 EDUCATIONAL CONTEXT
}

\author{
Cuong Viet Tran ${ }^{1,+}$, \\ Quang Hong Le ${ }^{2}$
}

\author{
Article History \\ Received: 17 September 2020 \\ Accepted: 15 October 2020 \\ Published: 30 December 2020
}

\section{Keywords}

Educations 4.0, teachers, students, school managers

\author{
${ }^{1}$ Thai Nguyen University of Education, Vietnam; \\ ${ }^{2}$ Xuan Giang High School, Hanoi, Vietnam \\ ${ }^{+}$Corresponding author $\bullet$ Email: cuongtv@tnue.edu.vn
}

\section{INTRODUCTION}

The industrial revolution has resulted in rapid and radical changes in many aspects of social life such as work, education, management, and everyday life (Blinder, 2006). Development brought about by the industrial revolution went through four phases from the middle of the $18^{\text {th }}$ century to the beginning of the $21^{\text {st }}$ century (Bloem et al., 2014; World Economic Forum, 2017; Assante et al., 2019).

We are in the midst of a dramatic transformation in the way we manufacture products by digitizing the manufacturing process. This transition was so compelling that it was called Industry 4.0 to represent the fourth revolution that happened in the manufacturing sector. From the first industrial revolution (mechanization through water and steam power) to the production and mass assembly lines using electricity in the second, the fourth industrial revolution will take what began for the third time with the adoption of computers and automation and enhancing it with intelligence. Although some consider Industry 4.0 to be merely a buzzword marketing buzz, the changes that are taking place in the manufacturing sector deserve our attention (Nafea \& Toplu, 2020; Jompong Mongkolvanich, 2013; Puncreobutr, 2016).

The World Economic Forum's New Economic and Social Platform aims to work with partners to provide better education, skills, and jobs to 1 billion people by 2030. The urgency around this agenda was further spurred by the COVID-19 crisis, and there was an unprecedented opportunity to explore actions required to provide new skills to the workforce, and new distribution mechanisms to learning and training, as well as a new learning ecosystem, to trigger the Labor Skills Revolution.

Many of today's kids will work in new types of jobs that haven't exist yet, with rising levels of both digital and socio-emotional skills in the coming years. The gap between education and employment is widening more and more due to limited innovation in the learning system, which is primarily designed to reflect a factory-style growth pattern. The fourth industrial revolution has caused educational systems to adapt. At the same time, the school closures caused by the COVID-19 crisis reveal the existing shortcomings of the world's education system. Without action, the next generation will not be prepared for the needs of the future, creating risks for both productivity and social cohesion. 
There is an opportunity for public and private sector leaders to re-establish the primary and secondary education systems while designing content and delivery to meet the needs of future children.

Based on the framework developed in the School of the Future, a new educational model for the fourth industrial revolution should be defined. The Education 4.0 initiative aims to better prepare the next talent generation through general education transformation.

Therefore, specific implementation proposals will be developed to facilitate the transition to Education 4.0 according to the structure and function of Vietnamese education system. Besides, the identification of the characteristics of school administrators, teachers, and students will help Vietnam make a flexible and successful educational transition.

\section{LITERATURE REVIEW}

With the development of technology and innovation, the production system, workforce, training and education have been affected. Faced with the fourth industrial revolution, scholars are studying possible changes in the education and skills of the future workforce. As the workplace develops, new competencies will emerge (Riveros, 2012; Ben Levin, 2010). Education can be divided into the following stages:

- Education 1.0 is an education that meets the needs of agricultural society. Knowledge has been a shift from teachers to students, and students focus on teacher explanation, IR1.0. The industrial revolution led to an increase in the number of people going to school, the state officially participated in the work of national education. Before that, the number of people attending school was limited to the elite, and education was mainly the responsibility of religious organizations (Ben Levin, 2010; Irianto, 2017).

- Education 2.0 is a kind of education system that meets the needs of the industrial society. The learning process focuses on acquiring technologies to be used in the work-life. Education 2.0 appeared when a large number of universities were born, associated with the rapid development of printing and publishing technology. During this period, the university mainly taught and researched and was not yet popular with the majority.

- Education 3.0 has developed to meet the needs of society by leveraging technology, marking the increasingly diverse emergence of technology in the classroom. In the early $21^{\text {st }}$ century, one can see many classrooms that have no chalkboards but instead are personal computers, interactive teaching facilities. The classrooms have diversified, and education has become universal.

- Education 4.0, developed in the early $21^{\text {st }}$ century, is expected to meet the needs of the innovation era. Industry 4.0 refers to the next stage of development of the manufacturing industry and was first launched by the initiative of German scholars, industrialists and government. Its purpose is to "enhance the competitiveness of the domestic manufacturing industry by computerization" (Baena et al., 2017, p.74). Education 4.0 will focus on more radically personalized learning. With the advent of a variety of digital learning content, students can choose what they want to learn from their goals. Digital learning systems also make the assessment more adaptive, providing feedback on learning performance along with suggestions for next learning content. Students are expected to produce and adopt new technologies that will contribute to the development of society in this process. (Ben Levin, 2010; Irianto, 2017; Puncreobutr, 2016).

All these new developments have resulted in disruptions in different areas of life, including education. IR 4.0 can be negative as it can threaten the school's existence. However, it can also be positive as it offers many opportunities for innovative research and classroom practice, which can then accelerate and optimize teacher productivity and learning outcomes. Therefore, students, teachers and professional administrators must be self-aware and adapt to this development. For example, the teacher of this digital age must be a teacher with the academic mindset of the $21^{\text {st }}$ century, have digital knowledge, continue to learn new things and be able to take advantage of the opportunities offered by IR 4.0 for better teaching. Integrating classroom activities with some of the online platforms through blended learning is a highly recommended teaching strategy for today's teachers.

In short, if they are implemented in a systematic and conscious manner, all developments of IR 4.0 will surely have a positive impact on the future realization of our national educational goals.

\section{RESEARCH METHODS AND RESULTS}

Qualitative research methods have been used in research to test thoughts on the concept of Education 4.0 in education. Qualitative research processes are used to draw a detailed and realistic picture of phenomena or events using qualitative data collection methods such as observations, interviews, and literature analysis. 
The basic qualitative research design, one of the qualitative research models, has been used in the study. The purpose of basic qualitative research is the most widely used qualitative research design in education to examine how individuals interpret their experiences, how they build perceptions of the world, and their meanings are tied to these experiences. In this study, it was decided that the basic qualitative research design is the most appropriate because it has been tested how teachers who are experts in the educational field, understand the meaning of the Education 4.0 concept.

\subsection{Research methods}

\subsubsection{Participants}

We use the "snowball sampling" method, which is a non-probability sampling technique (including intentional sampling), in which a researcher starts with a small sample of a few lecturers know about education 4.0 and extends the sample by asking the original participants to determine who else should participate in answering questions for the study. In other words, the beginning sample is small and then grows through the research process, like "a snowball growing".

A research group includes 10 lecturers working in the Faculty of Mathematics, Thai Nguyen University of Education; Faculty of Informatics and Faculty of Educational Administration of Hanoi University of Education in the academic year 2019-2020. In which, 3 lecturers are women, 7 are male; 2 of them are professors, 3 of them are associate professors, 4 of them are $\mathrm{PhDs}$, and 1 is a $\mathrm{Ph} . \mathrm{D}$. student.

The snowball sampling method is suitable for qualitative research; the participating lectures were selected by the snowball sampling method to reach individuals with prior knowledge of Education 4.0, a relatively new concept for Vietnamese education. The research team consists of 10 lecturers, including lecturers working in the Faculty of Mathematics, Faculty of Mathematics - Information, Faculty of Education, and Faculty of Education Management. The age of the faculty members in the research group is from 38 to 69, of which, 2 retired professors still participate in lecturing and guiding scientific research. Members' experience in education varies from 10 to 45 years.

\subsubsection{Data collection and analysis}

The study data was obtained through a semi-structured interview. The semi-structured interview is a very useful data collection tool as it is structured enough to emphasize certain aspects of the research problem and flexible enough to allow participants to present a new meaning of the research topic. In this study, Education 4.0 in schools was tested in terms of human capital and therefore, the interview format with the proposed structure is appropriate.

During the preparation of the data collection tool, the document was reviewed in detail on Education 4.0. After reviewing the document, the draft interview sample included 5 open-ended questions and exploration. The draft template was rearranged related to expert opinion received from two faculties at the Faculty of education management. A reminder of the structured interview question is formulated with the expert opinion as follows:

- What are your views on Education 4.0?

- How do you identify teachers in Education 4.0?

- How do you identify students in Education 4.0?

- How do you identify educational managers in Education 4.0?

Before interviews, volunteer lecturers were called or contacted by email to set up an appointment. Researchers introduce themselves and research purposes to the participants. Questions about the demographics of the participants were asked. The researchers then asked relevant open questions about education 4.0 to the participants. Interviews lasted from 15 to 20 minutes. To get detailed information about the questions, the interview is supported by exploration questions. In analyzing research data, content analysis techniques were used. Researchers recorded and took notes in diaries. The study data were analyzed by two different researchers; during data analysis, the two researchers regularly discussed until a consensus of results was reached.

\subsubsection{Study reliability, applicability, consistency, and limitations}

Qualitative research is, for its nature and purpose, different from quantitative research. Therefore, the criteria used to determine the validity and usefulness differ from those used in quantitative research (Krefting, 1991). In qualitative studies that focus on the comprehensive description of a single case rather than generalizing the results, the concepts of true value, applicability, and consistency are used instead for validity and reliability (Krefting, 1991).

In this study, to increase the authenticity, we regularly interview directly with participants, report in detail the results and explain the results. Also, a detailed document review was conducted to prepare interview questions and experts were consulted on these questions to provide real value to the research. 
Besides, to provide consistency, the analysis was performed by two independent researchers, and then their analytical performance was unified.

The limitation of this study is that Education 4.0 is a relatively new subject and only a few people have knowledge about it. Therefore, to emphasize the technological and pedagogical aspects of the subject, the participants are limited to the members of these faculties.

The other shortcoming is that the number of members participating is limited; the members are represented for only 3 universities while in Vietnam the number of universities in education is numerous. The limitations are due to the nature of qualitative studies that are often time-consuming and costly. Factors such as time, cost, and effort required led the researchers to survey only within 10 faculty members of the three universities.

\subsection{Research results}

The study findings were organized by four titles matching the sub-questions of the study. The researched results are related to the lecturers' perspectives on the basic characteristics of Education 4.0; students of Education 4.0; Teacher of Education 4.0 and Education managers of the school.

\subsubsection{Basic features of Education 4.0}

The first sub-question of the study is about the lecturers' perspectives on the basic features of Education 4.0. To get the results for the first sub-question, analysis was conducted following the answers given by the Education Science and Education Management experts to the interview questions. Analytical results show that, in the opinion of faculty members, the main components of Education 4.0 are open access, personal education, and capacity development, digital technology integration to education, learning environment, lifelong learning, discovery education, and multidisciplinary education. In open access, an open educational resource with open online courses is given as an example. In personal education, instructors refer to the preparation of individual learning content, creating adaptive learning environments and the use of learning analytics (Schuster et al., 2016; Puncreobutr, 2016).

In digital technology integration to education, several proposals have been made to utilize technological innovations such as artificial intelligence to enhance reality, cloud computing, and virtual reality in education. The continuous learning environment is explained with learning outside the classroom and learning anywhere and anytime. Lifelong learning, one of the most focused topics in the context of Education 4.0, has been linked to learning how to learn sustainably and develop continuously (Puncreobutr, 2016). Finally, discovery education has been explained for application-oriented learning.

\subsubsection{Qualification expected from students of education 4.0}

The second sub-question of the study is related to the lecturers' views on the professional qualifications expected from students of Education 4.0. The results indicate that the features that are presented to Education 4.0 students by the instructors are classified of collaborative skills in communication, technology skills, learning skills, and personal characteristics.

In terms of technical skills, students should have technological attitudes and behaviors such as having knowledge of cybersecurity, launching new information and technology, using technology effectively, and keeping up with technological developments.

Study skills include skills that require students to learn, acquire knowledge, and use cognitive abilities. It includes analytical thinking, problem-solving, critical thinking, creative thinking, distinguishing between right and wrong information, self-study skills, learning to learn, creating knowledge, and learning anywhere and at any time (Ciolacu et al., 2017; Schuster et al., 2016).

In terms of individual characteristics, students should be a researcher and an entrepreneur who is always willing to develop curiosity, productivity, to be adaptive, responsible, and persistent.

Besides, Education 4.0 involves skills such as self-study, creative thinking, problem-solving, critical thinking, communication skills, and cooperation. These skills prepare students for the real-life and needs of Industry 4.0 since these skills are valuable and indispensable resource for the organizations of the future. Such skills covered in the study and by study participants are the same skills as $21^{\text {st }}$ century (Ciolacu et al., 2017), including skills such as crosscultural understanding, learning, and innovative skills such as critical thinking, problem-solving, creative thinking..., and life skills such as flexibility, responsibility, initiative and adaptation... These are soft skills, requiring awareness to process, create knowledge, and adapt because the core of Industry 4.0 is change.

\subsubsection{Expected qualification from teachers of Education 4.0}


The third sub-question of the study is related to the faculty's views on the qualifications expected from Education 4.0 teachers. For this sub-question, the data analyzed were by the answers given by the trainers to the interview questions, and the results are as follows:

We see that teacher proficiency description of Education 4.0 is classified as technology skills, instructional skills, lifelong learning skills, and individual characteristics. It was determined that the topic-based skills, technology skills showed similarity with students' technology skills. However, technology skills for teachers of education 4.0 are defined as managing virtual groups of students and integrating technology with the teaching process. Similar to students, the individual characteristics expected from teachers for Education 4.0 are identified as curiosity, patience, and openness to change, adaptation, and investigation. For teachers of Education 4.0, lifelong learning skills have been paid more attention. For this reason, the lifelong learning skills for teachers of education 4.0 are integrated with learning skills, which are distinguished as follows: learning to innovate approach and maintain continuous professional development. It has been determined that the most important skill for Education 4.0 teachers is the instructional skill. In this context, it guides students in technology and pedagogy, emotionally engaging students, coordinating, motivating, leading, creating participation in the learning environment, helping students access correct information and help students set goals for emphasis. Here are some of the faculty views on the professional qualifications expected from teachers for Education 4.0.

The role of the teacher gradually increases in Education 4.0 as teachers play the advisory role. Teachers need selfimprovement skills to guide students in handling big data and digital environments, learn how to learn, and take precautions for cybersecurity. Teachers should guide students both in technology and pedagogy. Teachers should look for which application is best suited for their students. Teachers should ask themselves and investigate how they can better teach and how they can provide a better learning environment for their students. Teachers must be open to change.

3.2.4. Expected qualification of school leaders in Education 4.0

The last sub-question of the study is the description of the faculty's views on the qualifications expected from Education 4.0 school administrators. For the final sub-question, the data were analyzed according to the responses given by the trainers to the interview questions and the results are as follow:

The defining characteristics for school leaders of Education 4.0 are grouped into instructional skills, technology skills, academic skills, and technical skills.

Within the instructional skills of a school administrator, most are related to the skills of providing technology instruction at the school level; motivating all stakeholders, having vision, developing learning style, and leading others to use technology are emphasized. Similar to technology skills for teachers of education 4.0, the technology skills of school administrators are determined by technology development, effective use of technology, and the design of appropriate learning environments for students and data interpretation in education. On the other hand, technology skills like acquiring digital knowledge and integrating innovation into their schools are the markers for school management. It was found that academic skills such as problem-solving, critical thinking, and creative thinking... are common to all members of the school tested in this study.

However, it has been found that skills that differentiate school administrators from others are technical. Leadership technical skills include their skills based on their expertise in school management. In this range, skills include being an agent of change, coordination, collaboration and good, responsible communication, organizing, operating, empowering, and supporting participatory decision-making. Provide support differs from the school manager's traditional skills in terms of opportunities for idea innovation to develop technology, innovate, and invest in technology by providing required human resources and material (Hussin et al., 2015; Bass BM, Avolio BJ, 1990).

\section{DISCUSSION AND CONCLUSION}

The purpose of this study is to identify the basic skills and qualifications of the subjects in Education 4.0 when they were students, teachers, and school leaders (school leaders in Vietnam are usually the Principal). The product of Education 4.0 is so important that it will take responsibility for future generations of workers who will become the workforce of Industry 4.0. To achieve the main purpose of this study, members were interviewed. The primary level of proficiency is defined as the integration of digital technology with education, continuing learning environments, personal education, discovery education, and lifelong learning. The documents emphasize the use of digital technologies in the educational environment. Integrating digital technology with education is also accepted as one of the main prerequisites for innovation-based education, known as the educational model of the $21^{\text {st }}$ century. The 
technology-based education context is described as globalization, automation, virtualization, networking, and flexibility. This is also valid for continuous learning environments that are particularly emphasized from the anywhere and anytime learning perspective.

The results of the study described the requirements for teachers, students, and school leaders that meet the expectations of Education 4.0. The authors hope that this research result is an important document for Education 4.0 research in Vietnam.

\section{REFERENCES}

Assante, D., Caforio, A., Flamini, M., Romano, E. (2019). Smart Education in the context of Industry 4.0. 2019 IEEE Global Engineering Education Conference (EDUCON), Dubai, United Arab Emirates, 2019, pp. 1140-1145, doi: 10.1109/EDUCON.2019.8725057.

Bass BM, Avolio BJ (1990). Developing transformational leadership: 1992 and beyond. J. Eur. Industrial Train. 14:21-27.

Blinder, A. P. (2006). Offshoring: The next industrial revolution?. Foreign Affairs, 85(2), 113-128.

Bloem, J., Van Doorn, M., Duivestein, P., Excoffier, D., Maas, R. \& Van Ommeren, E. (2014). The fourth industrial revolution. Things to tighten the link between IT and OT. SOGETI: VINT Research Report 3 of 4.

Ciolacu, M., Tehrani, A. F., Beer, R., Popp, H. (2017). Education 4.0 - Fostering student's performance with machine learning methods. IEEE $23^{\text {rd }}$ International Symposium for Design and Technology in Electronic Packaging (SIITME), Constanta, pp. 438-443, doi: 10.1109/SIITME.2017.8259941

Hussin, Sufean., Al Abri, Saleh. (2015). Professional Development Needs of School Principals in the Context of Educational Reform. International Journal of Educational Administration and Policy Studies, 7(4), 90-97.

Jompong Mongkolvanich (2013). Organization and educational personnel management ( $2^{\text {nd }}$ ed.). Bangkok: Chulalongkorn University.

Nafea, R. M., \& Toplu, E. K. (2020). Future of Education in Industry 4.0: Educational Digitization - A Canadian Case Study. In Özbebek Tunç, A., \& Aslan, P. (Ed.), Business Management and Communication Perspectives in Industry 4.0 (pp. 267-287). IGI Global. http://doi:10.4018/978-1-5225-9416-1.ch015

Puncreobutr, V. (2016). Education 4.0: New challenge of learning. Theresa Journal of Humanities and Social Sciences, 2(2), 92-97.

Schuster K., Groß K., Vossen R., Richert A., Jeschke S. (2016). Preparing for Industry 4.0 - Collaborative Virtual Learning Environments in Engineering Education. In: Frerich S. et al. (eds) Engineering Education 4.0. Springer, Cham. https://doi.org/10.1007/978-3-319-46916-4_36

World Economic Forum (2017). ASEAN 4.0: What does the Fourth Industrial Revolution mean for regional economic integration?. https://www.adb.org

Riveros, A. (2012). Beyond Collaboration: Embodied Teacher Learning and the Discourse of Collaboration in Education Reform. Stud Philos Educ, 31, 603-612. https://doi.org/10.1007/s11217-012-9323-6

Irianto, D. (2017). Industry 4.0; The Challenges of Tomorrow. Presented at Seminar Nasional Teknik Industri, BatuMalang.

Laura Krefting (1991). Rigor in Qualitative Research: The Assessment of Trustworthiness. American Journal of Occupational Therapy, 45, 214-222. https://doi.org/10.5014/ajot.45.3.214 